\title{
Antigos processos e novas tendências da urbanização norte-americana contemporânea
}

\author{
Old processes and new trends in the \\ contemporary North American urbanization
}

Maria Floresia Pessoa de Souza e Silva

\section{Resumo}

Em 2010, a suburbanização permanece como característica dominante da urbanização contemporânea norte-americana (US Census, 2010), colaborando para o desinvestimento e declínio das áreas urbanas consolidadas. Projetos de renovação se multiplicam em harmonia às estratégias políticas e econômicas neoliberais e, muitas vezes, ocasionam a gentrificação, foco dos estudos referenciais de Neil Smith. Nesse cenário, duas tendências se fortalecem e introduzem novas relações socioespaciais às dinâmicas urbanas. De naturezas completamente diversas, as gated communities e a teoria urbanística do New Urbanism crescentemente são incorporadas ao repertório dos projetos urbanos elaborados para subúrbios e para áreas centrais, objetivando promover qualidade, sustentabilidade e/ou equilibrar desigualdades. A experiência empírica do Vale de Las Vegas ajuda a compreender como se dá essa complexa equação na prática.

Palavras-chave: gentrificação; urbanização dispersa; gated communities; New Urbanism; Las Vegas.

\begin{abstract}
Suburbanization remains as a dominant feature of contemporary urbanization in the United States (US Census Bureau, 2010), having contributed to the disinvestment and decline in inner urban areas. Renewal projects have been growing in consensus with neoliberal political and economic strategies and have often resulted in gentrification - a phenomenon with extensive reference in Neil Smith's works. Meanwhile, two trends have been strengthened, introducing new socio-spatial relations into the urban dynamics. Distinct by nature, the gated communities and the New Urbanism theory have been progressively incorporated in the scope of the urban and suburban projects that seek quality, sustainability and/or to balance inequalities. Empirical evidence found in Las Vegas Valley illustrates how this complex scenario has taken place in practice.
\end{abstract}

Keywords: gentrification; urban sprawl; gated communities; New Urbanism; Las Vegas. 


\section{Introdução}

Desde as últimas décadas do século $\mathrm{XX}$, duas novas tendências, de naturezas totalmente diversas, se apresentam trazendo soluções aos problemas da urbanização contemporânea norte-americana, orientando tanto projetos em novas áreas de expansão, quanto aqueles com intuito de renovar áreas degradadas, sejam essas centrais ou suburbanas. A primeira tendência refere-se às chamadas gated communities - GC (que se assemelham ao que conhecemos como condomínios fechados no Brasil), as quais se constituem em produtos explicitamente mercadológicos, caracterizadas por terem como pressuposto 0 isolamento físico do entorno associado a uma estrutura de gestão condominial privada, que, supostamente, tornam essas áreas menos susceptíveis à degradação provocada pelo desinvestimento público; a segunda tendência é o $\mathrm{New}$ Urbanism - NU, uma teoria urbanística com princípios e objetivos definidos, que defende a importância do bom desenho no combate às desigualdades socioespaciais (Charter of New Urbanism, 1996).

Sem pretensão de exaurir tema de tal amplitude, pretende-se aqui discutir duas questões que parecem ser essenciais: as $G C$ e o $N U$ reforçam ou minimizam os problemas da suburbanização? Que relação se observa entre a gentrificação resultante de intervenções para recuperação de áreas consolidadas e essas novas tendências da urbanização contemporânea?

0 texto inicia com a revisão de dois conceitos fundamentais a esse debate: a suburbanização e a gentrificação. Na segunda parte, considerando a diversidade dos problemas urbanos contemporâneos, busca-se verificar os princípios e objetivos das GC e do NU e conhecer seus resultados práticos, avaliando se são respostas válidas àqueles. Segue-se um estudo empírico que mostra como essas tendências têm se inserido à dinâmica urbana no Vale de Las Vegas, área que vivenciava um dos maiores índices de crescimento urbano do país até meados de 2000. Por fim, as conclusões apontam que ambas as tendências parecem mais contribuir para criar novos conflitos e ampliar as desigualdades socioespaciais que para solucionar os problemas urbanos.

\section{Atualizando os processos de suburbanização, renovação e gentrificação nos Estados Unidos}

\begin{abstract}
0 termo spraw/ tornou-se um novo americanismo, quando subdivisões e centros comerciais brotaram nas paisagens. No fim dos anos setenta, quando aumentaram as taxas de juros e a inflação alcançou dois dígitos e os preços das casas elevaram-se além do alcance das famílias jovens, o Departamento de Agricultura anunciava que, todos os anos, três milhões de acres agricultáveis estavam sendo urbanizados. Em 1985, as pessoas podiam com razão debater se os Estados Unidos eram uma nação racista, imperialista ou religiosa, mas, dificilmente, alguém poderia discordar sobre a designação de ser uma nação suburbana. (Jackson, 1985, p. 284) ${ }^{1}$
\end{abstract}

Em 1985, ao publicar um dos mais reconhecidos estudos sobre o fenômeno da suburbanização nos Estados Unidos: Crabgrass Frontier, The suburbanization of the United 
States, Kennet Jackson afirmou que entre 1950 e 1980, 18 entre as 25 maiores cidades americanas perderam população, enquanto os subúrbios ganharam 60 milhões de pessoas (dessas, 38 milhões teriam migrado nos primeiros vinte anos); entre as 15 maiores áreas metropolitanas existentes em 1970, somente uma cidade tinha maior população que os subúrbios: Houston, no Texas. Acrescenta que declínios foram também observados na Europa e na Ásia, mas o abandono do centro em direção aos subúrbios nos Estados Unidos se deu em uma velocidade dramática, com drásticas mudanças nos perfis étnico, social e econômico, algo considerado sem precedentes na história (Jackson, 1985).

A intensidade com que se deu a suburbanização norte-americana no pós-guerra tem, muitas vezes, levado à omissão de sua origem em meados do século XIX. Para uns, seu início estaria associado à fuga das elites econômicas e políticas das grandes cidades em busca de uma vida mais saudável próxima à natureza (Stilgoe, 1988; Fishman, 1987); para outros, ao crescimento industrial que conduziu massas de trabalhadores aos subúrbios, associado aos investimentos imobiliários especulativos, ambos espalhando "pedaços condensados de urbanidade nas periferias" (Walker e Lewis, 2004, p. 26). ${ }^{2}$ Observa-se a força do setor industrial nesse processo quando em 1900, um terço de todos os empregos em manufaturas nos Estados Unidos se localizava fora da área central e, em 1950, esse percentual já chegava a 50\%; também, das atividades comerciais, que, a partir dos anos 1920, desconcentraram-se rapidamente, rivalizando com os distritos comerciais do centro. Um exemplo seria Chicago, que em 1935 , teria $3 / 4$ de seus estabelecimentos comerciais localizados fora da área central (Bruegmann, 2005, p. 37)

Na segunda metade do século $X X$, esse deslocamento ganharia força e dimensão, quando as áreas centrais passaram a ser sinônimo de concentração da população que mais demandava subsídios do poder público, e que menos contribuía para suas receitas, os mais pobres. Os subúrbios, cada vez mais, ofereciam serviços privados, ambientes mais qualificados, tudo a um menor custo de vida. Como reflexo, a queda dos valores dos impostos sobre propriedade nas áreas centrais minimizavam receitas públicas e reduziam viabilidade de novos investimentos. Na opinião de Jackson (1985, p. 187), duas condições e duas causas foram necessárias para intensificar esse processo:

Claro, não há uma única resposta para um fenômeno de tal importância, mas vou argumentar que houve duas condições necessárias para desconcentração das residências dos norte-americanos - 0 ideal suburbano e o crescimento da população - e duas causas fundamentais o preconceito racial e a moradia barata. ${ }^{3}$

A industrialização acelerou o crescimento urbano desde o final do século XIX, e o desejo de possuir uma casa própria no subúrbio foi um sonho estimulado e facilitado pelas políticas públicas federais (viabilizando infraestrutura, garantindo hipotecas, ofertando vantagens fiscais aos proprietários). 0 preconceito racial estaria relacionado a dois fatores: evitar a convivência com os afrodescendentes que chegavam do Sul em busca de trabalho, após a Segunda Guerra Mundial; e, às novas políticas educacionais, que tornaram inconstitucional a separação racial nas escolas públicas a partir de 1954. A opção por morar nos subúrbios foi 
respaldada, entre outras coisas, pela condição econômica da maioria, pela estrutura fundiária, pelos avanços nas técnicas construtivas e pela decisão do poder público federal em expandir esse padrão de crescimento (Jackson, 1985; Duanes, Plater-Zyberk e Speck, 2000).

As críticas contra o spraw/ se iniciaram na década de 1960 associadas à imagem de um crescimento econômico, ambiental e socialmente insustentável. ${ }^{4}$ Ao concluir seu estudo, Jackson (1985) acreditava que no século vindouro, apesar do avanço tecnológico constituir-se em um potencial estímulo à suburbanização, outros aspectos imporiam a reversão desse fenômeno, dentre eles: 1) a conscientização de que o petróleo era finito; 2) a eficiência energética da tipologia multifamiliar permitindo reduzir custos de ar condicionado e calefação; 3) o aumento do valor dos imóveis, fruto do aumento do preço da terra e da falta de investimentos em novas tecnologias; ${ }^{5} 4$ ) a atratividade dos lucrativos mercados financeiros; 5) o crescimento das políticas públicas de conservação, renovação e trânsito de massa; 6) a crescente inserção das mulheres no mercado de trabalho, favorecendo o interesse pelas moradias sem jardins e mais próximas ao comércio, serviços e equipamentos; e 7) o aumento das minorias e a migração dos afrodescendentes para os subúrbios.

Contrariamente às previsões de Jackson (1985) a suburbanização cresceu nos Estados Unidos e passou a se expandir também em outros lugares do mundo, provocando novos estudos e revisão do conceito do sprawl. Nesse sentido, se antes o sprawl era considerado o padrão urbanístico suburbano, passa a ser entendido como um processo que pode assumir diferentes formas e que adquire um rigor quantitativo passível através da comparação ao longo do tempo, de distintas dimensões, combinadas ou não, entre elas: densidade, continuidade, concentração, agrupamento, centralidade, nuclearidade, usos mistos e proximidade (Couch, Leontidou e Petschel-Held, 2007).

Em 21 de outubro de 2011, na 39a Annual Conference of Nevada of the American Planning Association, realizada em Reno (NV), o representante do US Census Bureau, funcionário da Denver Regional Census Center, inicia seu discurso afirmando que os resultados do censo de 2010 revelaram cinco maiores tendências: 1) norte-americanos estão se tornando mais suburbanos; 2) a população está ficando mais velha; 3 ) nota-se relevante crescimento de minorias raciais e étnicas; 4) há significativas mudanças na composição familiar; 5) as regiões do Sul e Oeste continuam a apresentar os maiores níveis de crescimento. Assim, esse processo permanece reproduzindo, ${ }^{6}$ intensificando ou relocando os problemas já conhecidos, além de agregar novos, como a questão da insegurança, da densificação da periferia e da "gentrificação" dos antigos subúrbios (Marcuse, 2008; Sonovam, 2010; Bruegmann, 2006; Mckenzie, 2005).

Na opinião de Bruegmann:

[...] a mais convincente resposta à pergunta: por que razão o spraw/ tem persistido ao longo de tantos séculos, parece ser o crescente número de pessoas acreditar ser este o meio mais seguro para usufruir da privacidade, mobilidade e ato de escolha, que outrora estavam disponíveis apenas para os mais ricos e mais poderosos membros da sociedade. (2005, pp. $111-112)^{7}$ 
Por privacidade o autor entende "a habilidade de controlar seu entorno", vantagem essa antes só permitida aos muito ricos, mas que as mudanças na política habitacional e os incentivos ao formato condominial, permitiram reduzir custos de moradia e ampliar essa regalia para a classe média (Bruegmann, 2005, pp. 109-111).

Ao fim da Segunda Guerra Mundial, os empréstimos facilitados pelo governo federal e a existência de uma grande demanda levaram os empresários a se acomodarem, a repetirem fórmulas que desenhavam paisagens monótonas e ofereciam produtos de baixa qualidade. A partir dos anos 1960, esse quadro se reverteria, quando os empreendedores se alarmaram com a alta inadimplência das hipotecas, somada a um crescente número de imóveis vazios, ameaçando a comercialização de seus produtos. Nesse momento, a produção de condomínios - mais conhecidos nos Estados Unidos como Common Interest Development, CID - se mostrou como uma saída para a crise. 0 setor privado passou a destacar vantagens financeiras dos novos designs, acusar o zoneamento de ser arbitrário e inflexível, defender o uso multifamiliar e as altas densidades como meio de inovar seus produtos imobiliários e de reaquecer o mercado: agrupamento de conjuntos residenciais (cluster subdivisions), Planned-Unit Development - PUD - e zonas adensáveis (density zone), passaram, assim, a fazer parte do vocabulário e de publicações ${ }^{8}$ dos agentes desse setor (Babcock, 1966).

Outro fator que colaborou para popularização dessa opção de moradia entre os norte-americanos foi a financeirização do mercado da construção civil. Essa tornou a atuação dos financiadores tradicionais (seguradoras e fundos de pensão) mais agressiva e introduziu as grandes corporações nesse mercado que, mesmo sem nenhuma experiência prévia no setor imobiliário, mas visualizando a possibilidade de grandes lucros, passaram a figurar como novos e grandes investidores ${ }^{9}$ (McKenzie, 1994; Babcock, 1965). Assim, deu-se uma onda de fusões, aquisições e Joint Adventures, passando os empreendimentos imobiliários a serem negociados em bolsas de valores, a partir de sofisticados esquemas financeiros, e que teve como resultado a massificação do produto habitação. Todos esses esforços terminariam por convencer o Federal Housing Administration $F H A$, órgão da política nacional de habitação, a defender essa bandeira e estimular os CID (McKenzie, 1994).

Em paralelo, na esfera local, o "zoneamento" que desde a década de 1920 era utilizado como instrumento de controle urbano, baseado na separação rigorosa entre os usos, foi um dos grandes aliados para promover 0 sprawl (Babcock, 1966). Desde seu princípio, o zoneamento seria flexibilizado para incluir usos de menor "aceitabilidade" pelos residentes, evitando grandes embates, assim como também serviria para atender à localização de equipamentos públicos e o funcionamento das indústrias sem interferências da vizinhança (Walter e Lewis, 2004). As adaptações culminariam no que Babcock (1966, p. 11) chamaria de "máxima flexibilização", o "empreendimento planejado" (Planned Unit Development-PUD), quando o zoneamento assumiu a "improvisação judicial" : 
Cada proposta é julgada por seu mérito particular e os padrões pelos quais cada proposta será julgada são vagos. Com efeito, a PUD suplanta os dispositivos pré-existentes de zoneamento. Pactos e facilidades são barganhados entre empreendedor e município em lugar das costumeiras regulamentações de zoneamento [...]. (Babcock, 1966, p. 11) $)^{10}$

Fica claro que a forma condominial consolidou-se por meio da ação do governo - federal e local - em atendimento aos interesses do setor imobiliário (Babcock, 1965, pp. 46-51). 0 sprawl que durante o pós-guerra consolidou-se predominantemente através da difusão de um modelo ideal de moradia, que seria própria, de propriedade individual e tipologia unifamiliar, a partir dos anos 1960, a valorização do sistema de copropriedade seria a nova fórmula encontrada para sua persistência e viabilidade, a mesma que mais tarde viabilizaria a produção das gated communities e dos empreendimentos promovidos sob a teoria do New Urbanism.

McKenzie (2010, p. 53) adverte que o crescimento dos CID, desde os anos 1970, vem consolidando uma "dramática" e "silenciosa revolução no setor habitacional e na governança local" dos Estados Unidos. Em menos de 40 anos, o número de residências existentes dentro de CID passou de $1 \%$, em 1970, para $18,8 \%$, em 2008 , quando se estimou que 59,5 milhões de pessoas, aproximadamente $20 \%$ da população norte-americana, já residia sob o regime condominial administrado por associações de proprietários. 0 autor argumenta que daí decorrem três consequências "provavelmente irreversíveis": o enfraquecimento da estrutura dos governos locais, a transformação da natureza do regime de propriedade predominante em condominial e a reorganização do espaço urbano onde:

(...) A emergência de uma mentalidade fortificada e seu fenomenal sucesso é surpresa nos EUA, onde a maioria das pessoas vive em espaços abertos e vizinhanças sem proteção.

(...) Viver em uma GC representa a nova versão do sonho americano da classe média. Precisamente, porque, temporariamente, suprime e mascara, ou até evita e funde as ansiedades sociais e valores inerentes da vida urbana e suburbana moderna. (McKenzie, 2010, p. 13) ${ }^{11}$

Em 2010, o livro Insecurity America: how we got here and what we should do about, organizado por Hugh Gusterso e Catherine Bestenam, apontou diversos fatores que vinham contribuído para aumentar os sentimentos de insegurança e vulnerabilidade que hoje dominam a sociedade norte-americana: o declínio econômico do país; o desaparecimento e a volatilidade dos empregos; as dificuldades de superar a crise financeira; o aumento da imigração ilegal, criando novas cores para o racismo; a convivência obrigatória com questões imprevisíveis, como o aquecimento global e as ações terroristas; as derrotas militares; a inacessibilidade aos serviços de saúde; a crise imobiliária; e a exposição da pobreza nos espaços públicos; dentre outros.

Nesse cenário, as GC parecem ser a melhor representação de uma nova América: fortificada, fragmentada, mais desigual, parte das complexas transformações urbanas ocorridas nas últimas décadas do século $\mathrm{XX}$, orientadas pela economia global e pelas mudanças socioculturais. Elas transformam paisagens, comportamentos sociais e impõem novas 
relações jurídicas e institucionais (McKenzie, 1994, 2005, 2010; Blakely e Snyder, 1999; Lang e LeFurgy, 2007; Nelson, 2009; Low, 2010; Silva, 2012).

No final século $X X$, enquanto a suburbanização continua em ritmo acelerado, proliferam as alianças entre capitais públicos e privados no intuito de renovar áreas centrais que entram em declínio. Essas parcerias são expressões da substituição das políticas progressistas, frente ao fortalecimento do neoliberalismo, da internacionalização da economia e da competitividade entre cidades (Harvey, 1992, 1996). Segundo Neil Smith, esses processos de reestruturação ocorrem de diferentes maneiras em cada lugar. Seus estudos identificaram ciclos de desvalorização, os quais, por vezes, induziam à renovação urbana, por outras, não se completavam a ponto de gerar o interesse do capital em investir nas áreas degradadas, o que chamou de "renda diferencial" (rent gap):

A renda diferencial é a disparidade entre a renda potencial da terra e a renda atual da terra capitalizada sob o presente uso da mesma (...). A diferença entre as rendas é produzida principalmente pela desvalorização do capital (que diminui a proporção da renda da terra capaz de ser capitalizada) e também [pelo] contínuo desenvolvimento e expansão urbana (que historicamente tem elevado a renda potencial da terra no interior da cidade) (...) Somente quando essa diferença emerge, pode-se esperar investimento; uma vez que se a utilização atual conseguiu capitalizar toda ou a maior parte da renda da terra, pouco benefício econômico poderia ser derivado de um redesenvolvimento. Com a "filtragem" e declínio da vizinhança, a renda diferencial aumenta. Gentrificação ocorre quando a diferença é suficientemente ampla que os empreendedores possam adquirir imóveis mais baratos, pagar os custos do construtor e lucros da reabilitação, pagar juros ou hipotecas e empréstimos da construção, e podem então vender o produto final por um preço que traz retorno satisfatório para o empreendedor. A renda total da terra, ou maior parte dela, agora está capitalizada, o bairro é assim "reciclado" e começa um novo ciclo de uso. (Smith, 1996, p. 68) ${ }^{12}$

Assim, o reinvestimento em uma área exige que a mesma decline, ou se valorize, até atingir um determinado ponto, quando se torna economicamente viável para os empreendedores reinvestirem ali. Entre os possíveis investimentos, aqueles em propriedade assumem especial importância pela margem de lucro que possibilitam. Um problema recorrente resultante das tentativas de revitalização de áreas em declínio tem sido a gentrificação.

A gentrificação foi um termo cunhado em 1964 por uma das sociólogas europeias pioneiras no estudo desse fenômeno, a alemã Ruth Glass. Ao descrever as transformações que ocorriam no centro de Londres, reporta que a reabilitação do estoque de imóveis residenciais, aumentou seus preços, estimulou a substituição do inquilinato pela propriedade privada e a população trabalhadora por outra de maior renda. (Lee, Slatter e Wyly, 2008). No final do século XX, Smith sugere a revisão desse conceito, por esse já ser incapaz de acompanhar as transformações desse processo.

0 termo, cunhado por Ruth Glass, em 1964, tem sido usado para descrever os aspectos residenciais desse processo, mas isso está mudando, da mesma forma que a gentrificação evolui. (Smith, 2000 apud Lee, Slatter e Wyly, 2008, p. 9) ${ }^{13}$ 
A experiência pioneira da cidade de Nova York, iniciada na década de 1970, possibilitou verificar que a gentrificação teria acontecido em três "ondas" separadas por dois períodos de transição. Smith (2006) descreveu que a primeira onda aconteceu no final da década de 1970, de forma esporádica e era considerada uma "anomalia local"; a segunda iniciou-se no final daquela década até início de 1980, momento em que a gentrificação passou a ser vista como um movimento amplo e sistematizado que reformulava econômica, social e politicamente o espaço urbano; e a terceira onda sobreveio a partir dos anos 1993-4, quando a gentrificação se tornou "generalizada" como uma "estratégia urbana articulada" (p. 73), por meio da qual se produz habitação, lazer, emprego, novas paisagens aparentemente democráticas, de livre acesso, mas que na verdade são espaços de consumo direcionado àqueles que podem consumi-las. Aos poucos, a gentrificação passou a ser reportada tanto em outras cidades menores norte-americanas e em outros países, deixando de ser privilégio das cidades globais. Na explicação do autor, a gentrificação tendia a se expandir, atingindo distritos mais afastados, orientada por uma relação entre políticas de investimento e de desinvestimento.

[...] Quanto menores tiverem sido os investimentos na periferia [esclarece em nota que trata de periferia rica], menores são os desinvestimentos nos bairros abandonados e menor terá sido a difusão da gentrificação. Por isso mesmo, nas cidades em que a maior parte da extensão espacial é mais recente e nas quais as oportunidades de desinvestimentos prolongados foram circunscritas, do mesmo modo a difusão da gentrificação será limitada. (Smith, 2006, p. 78)
Ao pesquisar sobre os processos e formas urbanas que materializam a hegemonia do pensamento e do Estado neoliberal nos Estados Unidos, no período entre 1970-2000, Jason R. Hackworth (2007) analisa a gentrificação em diferentes escalas - da cidade e entorno, da área central, do bairro e do empreendimento ${ }^{14}$ e argumenta:

Essa análise revela o óbvio crescimento na periferia das cidades nos últimos trinta anos, mas [também que] mudanças populacionais e investimentos imobiliários na área central é bem menor que supõe a maior parte da literatura sobre a suburbanização contemporânea. As áreas de maior declínio e volatilidade não estão geralmente no interior da cidade, mas sim no interior dos subúrbios.

Finalmente numa escala menos abstrata, três formas emergentes parecem dominar a concertação espacial neoliberal. Suburbanização continua em um ritmo rápido, mas não é a simples extensão dos padrões do modelo keynesiano. Crescimento na periferia, hoje, parece estar profundamente ligado a uma polarização social mais abrangente. Os locais de crescimento suburbano mais dinâmicos são muitas vezes lugares onde as segundas residências e as atividades de lazer dominam. Em contraste, a habitação suburbana do período keynesiano gerencial é em grande parte vítima de desinvestimento, quando os ricos fogem tanto para os bairros gentrificados no interior da cidade ou para o interior das gated communities nas exurbias. 0 centro urbano, além disso, parece ser revalorizado em várias cidades, lançando algumas dúvidas sobre a descrição de gentrificação como um processo isolado. (Hackworth, 2007, pp. 96-97, grifos nossos) $)^{15}$

0 autor conclui que, "de modo geral, gentrificação é agora mais corporativa, mais 
facilitada pelo Estado e possui menos resistência que nunca" (Hackworth, 2007, p. 149), acrescenta que tem servido para oportunizar lucros ao mercado imobiliário, mas também para substituir paisagens típicas da administração keynesiana - habitação social, espaços públicos - por outras onde predominam espaços subordinados à gestão privada, parte deles resultado de megaprojetos ${ }^{16}$ e, acrescentamos, pelos enormes empreendimentos residenciais administrados por associações de proprietários. Lee, Slater e Wyly (2008, pp. 173-180) baseados na teoria de Smith, defendem que a partir de 2001, os Estados Unidos vivenciam uma quarta onda, caracterizada por uma maior conexão entre gentrificação local e capital nacional e internacional, e, também, pelo maior encorajamento das políticas estatais.

Nas áreas mais industrializadas, subúrbios construídos ainda no século XIX, ou início do século $X X$, há muito entraram em declínio principalmente pelo desmantelamento do setor industrial e de suas consequências no mercado de trabalho e na renda da sua população (Hanlon, 2007). Outros fatores também colaboraram, como a contínua atratividade dos novos subúrbios, a popularização do automóvel e os altos investimentos em infraestrutura viária (Davis, 1993). No sentido inverso, subúrbios que foram historicamente espaços de moradia da elite, ou aqueles que guardam características históricas relevantes, conseguiram se manter valorizados; e outros ainda, se "gentrificaram" (Hanlon, 2007).

No início do novo século alerta-se que a próxima crise urbana nos Estados Unidos ocorreria nos subúrbios de meia idade (referindo-se àqueles construídos entre 1945 e
1970), afirmando serem muitos deles sendo atingidos pelo desinvestimento, já vivenciavam mesmos sintomas de declínio dos centros urbanos. ${ }^{17}$ Em especial, aqueles localizados mais próximos das áreas centrais teriam como causa de sua decadência a idade do estoque habitacional, mas também aspectos étnicos e raciais, disponibilidade de empregos em manufaturas, entre outros. Os estudos de Hanlon (2007) confirmaram que o maior declínio vem ocorrendo entre os subúrbios construídos no pós-guerra e acrescenta que os custos da terra, da moradia e transportes, são fatores preponderantes dessa equação. Ao comparar os subúrbios construídos no pós-guerra com os mais recentes, avalia mudanças no perfil populacional, renda, dados sobre pobreza, habitação e saúde fiscal. Nas suas conclusões aponta que três entre cada 20 antigos subúrbios estão enfrentando o declínio, enquanto essa relação baixa para três em cada 50 novos subúrbios.

Relatórios oficiais do governo também reportam o problema:

Edifícios abandonados e subutilizados e o declínio das atividades econômicas não se limitam às cidades. Na verdade, as comunidades suburbanas mais antigas são agora vítimas de um mesmo ciclo de declínio [...] À medida que os ciclos de declínio espalharam-se a partir do núcleo urbano, estes subúrbios envelhecidos começaram a sentir muitos dos mesmos problemas das cidades. A renda familiar caiu, aumentou a criminalidade, as escolas tornaram-se problemáticas, sinais de ferrugem ficaram aparentes - tudo acelerando o movimento para subúrbios ainda mais distantes. (US Federal Government, 2000, pp. 12-13) ${ }^{18}$ 
Bruegmann (2005, p. 57) reporta que os novos subúrbios se expandem de forma mais lenta e mais densa ${ }^{19}$ (em especial no Sul e Oeste norte-americano), priorizam tipologias multifamiliares, e seus lotes vazios escasseiam. Como resultado, Los Angeles, a epítome do sprawl, no início deste século, passou a ser a cidade mais densa do país (p. 63). Destaca como novo fenômeno (mais visível no Nordeste dos Estados Unidos) a ocupação do limite mais longínquo, exurbia, onde cidades de interior (farm towns) são "gentrificadas" e transformadas em cidades dormitórios (commuter communities). Pondera que, enquanto a decadência de alguns subúrbios pós-guerra tem possibilitado o acesso a outra classe de menor renda em ascensão, outros subúrbios conseguiram manter-se valorizados até início do século XXl; e aqueles meIhor servidos e com melhor acessibilidade estão sendo "gentrificados", e explica:

Ao invés de diminuir, muitos subúrbios, geralmente aqueles com elementos naturais e boa acessibilidade, tornaram-se cada vez mais gentrificados. Um dos resultados mais visíveis presente tem sido o aumento dramático do número de desmontes (teardowns): a substituição de casas menores por outras muito maiores. (Bruegmann, 2005, pp. 69-70, grifo nosso $)^{20}$

Verifica-se que o termo "gentrificação" passa a ser utilizado com relação a outras áreas, consolidadas, também alvos de prolongado desinvestimento e declínio, mas espacialmente mais distantes dos centros. Semelhante aos projetos para as áreas centrais decadentes, o declínio dos subúrbios almeja projetos de renovação que promovam sua revalorização imobiliária e que podem resultar na substituição da população existente por uma de maior renda. $A$ solução, via de regra, passa por novos investimentos privados (estoque imobiliário) e públicos (normalmente na forma de flexibilização das leis, na facilitação de infraestrutura e serviços). Nesse contexto, a transformação desses subúrbios em GC se apresenta como um potencial mecanismo para resolver seus problemas ao oferecer dupla solução: combater o crescente sentimento de insegurança da população e "congelar" a área, impedindo sua decadência natural pelo envelhecimento de seus imóveis. Da mesma forma, a teoria do $N U$ oferece um arsenal de instrumentos para combater a deterioração dos espaços, como a densificação, o maior uso dos espaços públicos e o controle do percentual de habitação social.

\section{Gated Communities e New Urbanism - soluções viáveis aos problemas da urbanização contemporânea norte-americana?}

No final do século $X X$, duas tendências oriundas de naturezas completamente distintas, oferecem soluções aos problemas decorrentes da urbanização contemporânea, tanto àqueles provenientes da suburbanização, quanto para renovar áreas em declínio. A primeira é a teoria do New Urbanism - NU - e a segunda são as gated communities - GC. Ao considerar a diversidade dos problemas gerados pelo sprawl e daqueles vivenciados pelas áreas consolidadas em decadência, parece pertinente verificar de onde surgiram essas tendências, quais seus princípios e objetivos e quais seus resultados práticos. 
A teoria do New Urbanism surgiu nos Estados Unidos sob influência do British Neotraditional Town Planning (NTP), levado a cabo pelo Príncipe Charles e o arquiteto Leon Krier na Inglaterra, que "pretendia recriar as cidades pré-industriais na Europa pós-industrial" (Soja, 2000, p. 248). É identificada como fruto do crescimento do movimento do Smarth Growth, que tem entre seus pressupostos a valorização do senso de comunidade; otimização do dinheiro público; melhorias para o transporte, a mobilidade e qualidade do ambiente urbano; tudo isso com a garantia de desenvolvimento, da proteção dos investimentos existentes na vizinhança e retorno rentável aos empreendedores (Freilich apud Callies, Freilich e Roberts, 2004, p. 682).

Em 1993, o primeiro Congress for the New Urbanism, realizado na cidade de Alexandria (VA) seria o primeiro passo para formação dessa nova teoria urbanística que visava enfrentar o sprawl e promover o desenvolvimento inteligente das áreas urbanas nos Estados Unidos, transformando radicalmente os parcelamentos tradicionais. Três anos depois, durante seu IV congresso, a elaboração da "Carta do New Urbanism", consolidou seus princípios e objetivos, cujos ponto-chaves seriam os sistemas de transporte público articulados, espaços urbanos compactos e esteticamente planejados, o planejamento em diferentes escalas (do bairro, da cidade e da região) e o envolvimento das comunidades (The charter of the new urbanism, 1996). Desde então, renomados profissionais e acadêmicos passaram a difundi-la, incluindo a criação de disciplinas e grupos de pesquisas em universidades de peso, como a de Berkeley (CA). ${ }^{21}$ Sua aceitação crescente entre os agentes do mercado imobiliário, empreendedores e planejadores públicos e privados, conta ainda com grande apoio da mídia, associado à liderança do arquiteto Andres Duany da Flórida, considerado um dos gurus dessa teoria. ${ }^{22}$

Desde o princípio, essa teoria vem sofrendo críticas severas, que segundo Ellis (2002), podem ser agrupadas sob três aspectos: ideológicos, estéticos e sobre a distância entre sua teoria e prática. Entre os principais argumentos essas destacam: aspectos formais relacionados à arquitetura e ao urbanismo que perseguem um modelo intermediário entre a fantasia da Disney e as tradições das pequenas cidades do início do século XX; aspectos funcionais, quando a localização de seus projetos se dá prioritariamente nos subúrbios, e não nas áreas centrais como preconiza; e aspectos sociais, quando colaboram na formação de enclaves "homogêneos" para as classes de média e alta renda (Davis, 1992; Harvey, 2005).

Marcuse (2008) adverte que as cidades do início do século $X X$, que hoje inspiram a teoria, na verdade eram espaços produzidos por uma sociedade com perfil agrário, antidemocrática e antiurbana, que desejava estabilidade, defendia a casa própria, valorizava as relações familiares e as comunidades raciais e financeiramente homogêneas. Nesse sentido, diz não surpreender que os projetos do $N U$ tendem a produzir espaços socioeconomicamente homogêneos, prioritariamente de brancos e ricos. Lehrer e Milgrom (1996 apud Ellis, 2002) afirmam que alterações introduzidas no padrão arquitetônico dos projetos do $N U$ (varanda na frente da casa e garagem nos fundos, recuo frontal reduzido, proporcionalidade da edificação e uso de materiais originais que transmitam honestidade e simplicidade) costumam desagradar novos compradores. Acrescentam que através do uso 
de contratos restritivos conseguem impedir a desordem e as surpresas típicas dos ambientes urbanos reais.

Alex Krieger (2006) chama atenção que sua prática tem antes expandido subúrbios ao invés de preencher vazios em áreas já urbanizadas. Marcuse (2008) sugere chamá-la New Suburbanism, advertindo que sua prática tem contribuído para densificar subúrbios e reduzir o spraw/ na periferia dos mesmos; entretanto, aumentam o spraw/ na escala regional, reforçando distâncias e o uso do carro entre esses novos núcleos densos e a área central, terminando por criar um novo tipo de suburbanização. Observamos que esse resultado ocorre quando não relaciona dimensões máximas, densidades e localização de seus projetos, fazendo com que as mesmas regras de altas densidades sirvam tanto aos pequenos projetos circunscritos em áreas centrais, como àqueles com dezenas ou milhares de acres nos subúrbios.

Seus projetos em áreas centrais apresentam números pouco expressivos e são criticados, entre outras coisas, por não conseguirem dar sustentabilidade ao transporte público e por induzirem a gentrificação. Explicitamente sugerem que os projetos de renovação não ultrapassem o percentual de $10 \%$ de habitações populares, considerando ser o "ideal" para conseguir uma mistura social sem ameaçar o valor das propriedades da vizinhança (Duanes, Plater-Ziberk e Speck, 2000).

Callies, Freilich e Roberts (2004) avaliam ser os maiores empecilhos a sua implementação, os códigos de zoneamento e padrões viários que frequentemente requerem flexibilização. Acrescentam que para contornar esses obstáculos os projetos têm largamente empregado a utilização de contratos privados:
Apesar de as comunidades do NU parecerem cidades, poucas são incorporadas como municipalidades. Ao invés disso, elas se apoiam principalmente nas "Convenções, Contratos e Restrições" (CC\&Rs) e associações de proprietários (HOAs). Por um lado, o uso de contratos privados possibilita o uso de maior criatividade nos desenhos [dos projetos] em resposta às necessidades das comunidades. (Callies, Freilich e Roberts, 2004 , p. 725 , grifos nossos) ${ }^{23}$

Os mesmos autores apontam que os principais desafios para passar da teoria à prática do $N U$ seriam a inflexibilidade jurídica em relação aos usos mistos e às adaptações edilícias posteriores; as demandas dos outros usos versus as do uso habitacional; a não opção de arrendamento total ou parcial das unidades; a resistência, por parte dos consumidores e construtores às inovações urbanísticas e arquitetônicas citadas acima, como também, à inexistência de muros que limitem o livre acesso e o uso por qualquer cidadão de suas áreas privativas comuns (Callies, Freilich e Roberts, 2004, pp. 725-732).

Se a teoria tem sido bem aceita entre os planejadores, administradores e políticos (Grant, 2007), na prática, seus projetos ainda não alcançaram o mesmo grau de aceitação entre os consumidores que as $G C$; mesmo assim, registra-se um número crescente de projetos nos Estados Unidos e no mundo. ${ }^{24}$ Em 2002, a publicação New Urban News mostrava que havia 272 empreendimentos em construção ( $28 \%$ a mais do que um ano antes) e mais 200 em fase de planejamento, além de inúmeros projetos híbridos que incorporam a teoria parcialmente. Dez anos depois, a website do NU afirma que esse número já chega a quatro mil, entre 
empreendimentos planejados ou em construção, sendo $50 \%$ deles em centros históricos. ${ }^{25}$

Seus seguidores continuam a rebater suas críticas:

[...] após uma análise atenta, muitas críticas do New Urbanism apresentam problemas característicos. Os principais deles são o uso da caricatura, a amostragem inadequada de projetos, limitada compreensão dos princípios do New Urbanism e de suas práticas, julgamentos prematuros, expectativas irreais e viés ideológico. No final, o New Urbanism não pode satisfazer todos os seus críticos, porque eles exigem mudanças contraditórias. A esquerda aponta que o New Urbanism falha em não produzir uma crítica radical do capitalismo, enquanto economistas de direita atacam o seu apoio ao planejamento regional. Arquitetos e urbanistas criticam o New Urbanism por não ser suficientemente "urbano", enquanto os devotos do sprawl se opõem aos projetos do New Urbanism por utilizar densidades muito altas. Talvez os New Urbanistas tenham encontrado um meio termo razoável entre esses extremos, que torna possível hoje construir. (Ellis, 2002, p. 283) ${ }^{26}$

0 new urbanist, Peter Calthorpe, no livro editado por Michael Leccese e Kathleen McCormick: Charter of the New Urbanism (2000), defende que o $N U$ não se trata de nostalgia e acrescenta que seus críticos se limitam a enxergar a escala dos bairros, sem buscar compreender a escala regional.

No website do $N U$, ao lado de seus objetivos, está a pintura Bal du Moulin de la Galette, de autoria do artista francês impressionista Pierre-Auguste Renoir (1876) (Figura 1). A obra retrata a vida real, a multidão, a diversão da classe trabalhadora numa típica tarde de domingo, no final do século XIX, no Moulin de la Galette, bairro parisiense de Montmartre. Um espaço público convencional, vivo, apropriado pela multidão, com alta densidade e visível espírito de comunidade. Os objetivos falam em promover ambientes novos, ou restaurar existentes, tornando-os espaços de diversidade (de usos, racial, étnica, de habitação), acessíveis e compactos, vivos, tudo numa versão fashion, moderna, capaz de produzir "comunidades completas". Curiosamente, essa obra de arte está cotada entre os dez quadros mais caros do mundo, ${ }^{27}$ o que de forma sutil (ou ingenuamente?) deixa transparecer a sofisticação da proposta, ou talvez de seus consumidores. Sua prática, assim, parece ser um simples reflexo de suas contradições inerentes, coerentes com os pressupostos neoliberais e, em menor escala, do Smarth Growth.

A segunda tendência que se apresenta na urbanização contemporânea são as gated communities. Completamente diversas da primeira, sem regras ou princípios formalizados, têm como único objetivo atender às necessidades e aos desejos de seus ávidos consumidores. Apontadas como herança dos "espaços defensivos" de Oscar Newman (1973, apud Grant, 2007; Roitman, Webster e Landman, 2009), suas principais características são, conforme mencionado anteriormente, o isolamento do entorno, o acesso controlado através de barreiras físicas explícitas ou tecnológicas; o controle da paisagem (arquitetura, urbanismo e paisagismo) e da comunidade por meio de regras contratuais rigidamente administrados pelas associações de moradores e/ou administradores. Valores comunitários, nostálgicos ou tradicionalistas somente serão considerados se agregarem mídia positiva para valorizar e vender imóveis (Silva, 2012). ${ }^{28}$ 
Figura 1 - Bal du Moulin de la Galette

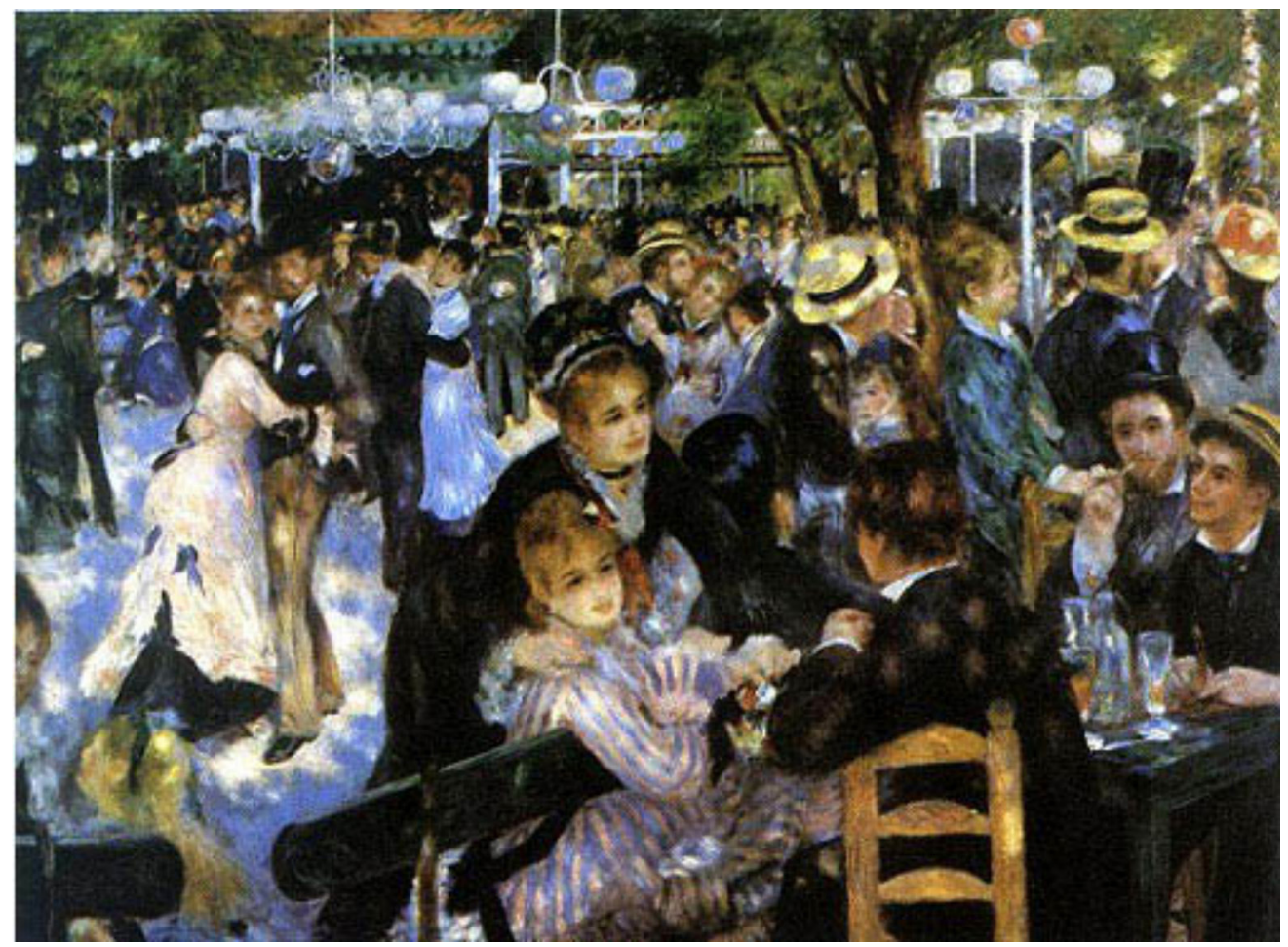

Fonte:<http://www.productionmyarts.com/Images/renoir/renoir-bal-au-moulin-de-la-galette-1876.jpg>.

Em 1996, já se estimava que 19\% dos CID existentes nos Estados Unidos, eram murados (Blakely e Snyder, 1999). A importância desse fenômeno levou a American Housing Survey levantar pela primeira vez dados sobre as GC em $2001 .{ }^{29} \mathrm{~A}$ pesquisa então afirma que $5,9 \%$ da população residiam nesses enclaves. Esse percentual, entretanto, variava bastante por região, chegando a $11,1 \%$ na região Oeste e $6,8 \%$ na Sul. Importante observar que estudos específicos mostram que, ao reduzir a escala de observação, esses percentuais se elevam consideravelmente. Como exemplo na cidade de North Las Vegas se estimava que $90 \%$ de sua população em meados de 2000 morassem em GC (Lang e LeFurgy, 2007).

Os adeptos do New Urbanism afirmam que as duas tendências têm ideologias opostas e enfatizam que o $N U$ abraça a cidade, enquanto os portões dos GCs a expulsa (Grant, 2007); entretanto, na prática, elas parecem caminhar em uma mesma direção. Grant (2007) afirma que, apesar dos planejadores (públicos e privados), no Canadá e Estados Unidos, se alinharem, em geral, aos princípios do New Urbanism, na prática eles estão, cada vez mais, supervisionando a construção de GC por conta da maior aceitação deste último pelo público 
consumidor. Segundo Grant (2007, p. 482), embora o NU e as GCS sejam "abordagens de desenvolvimento com objetivos e valores radicalmente divergentes, eles podem, inadvertidamente, levar a resultados semelhantes em "enclaves suburbanos": paisagens de privilégios, que separam e dividem" e que são essencialmente representações da "ascendência do privado sobre os interesses públicos" (Grant, 2007, pp. 481-482). ${ }^{30}$

Ambas tendências, tem sido difundidas e adaptadas em um mercado imobiliário globalizado, onde as GCs têm se multiplicado em uma velocidade estonteante (Silva, 2012; McKenzie, 2010; Low, 2010; Glazse, Webster e Frantz, 2006). Em comum, as duas demonstram a preocupação com a construção do "sentimento de comunidade", mesmo quando atendem a diferentes objetivos. Enquanto os seguidores do $N U$ acreditam que a qualidade do espaço irá contribuir para formar um real senso de comunidade e dirimir diferenças sociais, étnicas e econômicas, as CGs descartam qualquer papel pedagógico e apostam explicitamente na não diversidade, na autoexclusão, no pragmatismo do mercado, com a crença de que o comunitarismo somente pode ser produto da homogeneidade.

\section{Vale de Las Vegas - relacionando processos e tendências urbanos nos Estados Unidos}

0 Vale de Las Vegas consiste na área mais urbanizada do condado Clark County, ${ }^{31}$ que por muito tempo foi vista como uma exceção nacional, especialmente pela sua economia baseada na indústria do jogo. Nas últimas décadas, tem sido apontada como novo paradigma urbano norte-americano, dada sua relevância na difusão de novos padrões de comportamento social, cultural, inovações na arquitetura e nas mudanças econômicas observadas no país, o que levou à criação do termo Las Vegasnization (Hess, 1993; Littlejohn, 1999; Schumacher, 2004; Gottdiener, Collins e Dickens, 2009). Seu espaço parece ser a melhor síntese dos espaços urbanos contemporâneos norte-americanos, seja no que toca ao urbanismo espetáculo, com cenários temáticos de dimensões hiperbólicas em ambientes altamente densos, seja na imensidão da sua suburbanização dispersa.

Escondida atrás dos arranha-céus e da profusão de imagens e luzes da Strip (como é popularmente conhecida sua mais famosa avenida Las Vegas Boulevard), área de maior concentração de cassinos e resorts, seus subúrbios se estendem até seus limites mais extremos, semelhante a tantos outros espaços urbanos no Sun Belt. Até meados de 2000 esta área foi um dos recordes de crescimento da nação, tendo como três maiores forças de atração: 0 turismo, a oferta de emprego e impostos convidativos (Sonovam, 2010). Um bom exemplo de como vinha ocorrendo esse processo pode ser o mega projeto Coyote Springs, originalmente pensado para construir 49.600 residências em uma superfície de $52.610 \mathrm{~km}^{2}$, numa área onde só existiam fazendas e ranchos, prevendo um prazo de execução de 30 anos.

Em meados de 2000, o Vale de Las Vegas recebia uma média de quatro mil novos residentes por mês (Schumacker, 2004), cuja demanda por moradia fez explodir a indústria 
da construção civil e seu mercado imobiliário. Dada a crescente escassez de áreas disponíveis para novos projetos, as alternativas eram a verticalização ou maior invasão das áreas rurais; segundo o setor de planejamento de Clark County, a segunda opção prevalecia. ${ }^{32} \mathrm{Em}$ 2010, a população do estado de Nevada era de 2.700 .551 habitantes, tendo crescido $35,1 \%$ entre 2000 e 2010, enquanto a população nacional cresceu 9,7\%. 0 condado de Clark County cresceu no mesmo período $41,8 \%$ (quatro vezes mais que a nação) e a Cidade de North Las Vegas, 87,9\%. ${ }^{33} 0$ condado em 2010 já tinha 1.951.269 residentes (US Census, 2010).

Esse processo colaborou para recrudescer o processo de declínio do centro e acirrar a competição entre a cidade de Las Vegas e Clark County. 0 abandono do centro iniciou-se no final da década de 1940, quando a indústria passou a optar por localizar-se no subúrbio, em território pertencente ao condado, onde havia grandes glebas disponíveis a preços acessíveis, legislação mais flexível e incentivos fiscais convidativos. Era o princípio da Strip. Enquanto novos investimentos públicos e privados (universidade, aeroporto, shopping, complexos residenciais) passaram a se direcionar para essa nova área, o centro histórico, a Fremont Street e suas adjacências decaíam.

Desde a década de 1980, inúmeros projetos pensados na forma de parcerias público-privadas tentam colocar essa área central de novo no mapa do turismo, sempre numa visível competição com o condado, que passou a abocanhar a maior parte da milionária receita da indústria. Em 1987, foi realizada a primeira parceria visando edificar um novo e moderno resort para a área, que contou com investimentos do governo local no valor de 17 milhões de dólares. 0 fracasso desse empreendimento o fez fechar as portas meses depois de sua inauguração, dando margem para muitas críticas, mas abrindo caminhos para novas parcerias que, cada vez mais, incluíam novos atores e maiores propósitos. Em 1995, o projeto Fremont Street Experience (Figura 2) criou um shopping aberto, um calçadão sobre quatro quadras desta via coberto com telões, e envolveu os maiores empreendedores da área. Três anos depois, uma segunda fase desse projeto chamou-se "Neonmetropolis" e veio na linha de diversificar suas atividades, trazendo teatro, restaurantes e shoppings que pudessem competir com os investimentos da Strip, entretanto, não vingou. Outras parcerias menores ocorreram nessa mesma década, uma delas com intenção de preservar prédios históricos teve sucesso pontual e limitado.

Enfim, no início do ano 2000, um grandioso novo projeto, também em parceria com o setor privado, foi pensado para uma gleba de 61 acres. Contando com apoio do poder local previu a implantação de um centro médico de Cleveland, cujo projeto apostou na arquitetura de grife assinada por Frank Gehry (Figura 2), e de um centro de artes que surtiu pouco sucesso. Esse projeto conseguiu atrair outros investidores privados, como o Premium Out-let e um enorme mercado para móveis que hoje se destacam na paisagem da área. Ainda, logrou oferecer habitações de melhor padrão na intenção de promover mistura social, mudando o cenário dessa área caracteristicamente habitado por pessoas de baixa renda. 0 resultado desse intento conseguiu produzir algumas $G C$, de acesso restrito e esquemas de segurança privada, que foram prioritariamente ocupadas por casais sem filhos e pessoas solteiras, principalmente 
Figura 2 - O projeto Fremont Street Experience

e o novo projeto de Frank Gehry

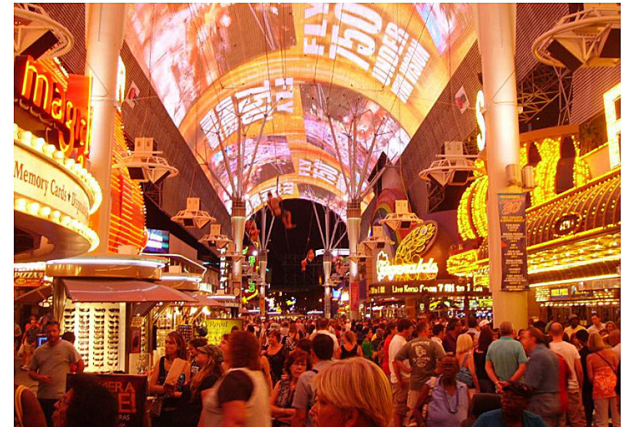

Fonte: Acervo da autora (2011).

dada a má qualidade das escolas públicas nesse local. Por fim, mais uma parceria, vislumbrou um VLT com a função de ligar a Strip à Fremont Street, o qual só foi parcialmente implantado, servindo para aumentar a mobilidade na Strip. Iniciando a segunda década do novo século, a Fremont Street e suas imediações continuavam sendo um ilustre desconhecido para a maioria dos milhares de turistas que chegam ao Vale. Ali pouca coisa mudou, predominando a imagem de declínio com seus hotéis baratos, habitação social, atendendo uma "clientela de segunda classe" (Schumacher, 2004), enquanto os turistas de maior renda preferem a suntuosidade e variedade de ofertas da Strip.

Enquanto isso, nos subúrbios, se formava uma nova fronteira imobiliária (Figura 3), consolidando um novo tipo de suburbanização, a qual priorizava projetos mais densos, em formato condominial, na sua maioria GC. Os dados da American Housing Survey, em 2005, mostram que Las Vegas possuía a maior concentração de GC dentre as áreas metropolitanas, seguida de Phoenix (Lang e LeFurgy, 2007, p. 101). Em 2008, a cidade de Las Vegas reporta

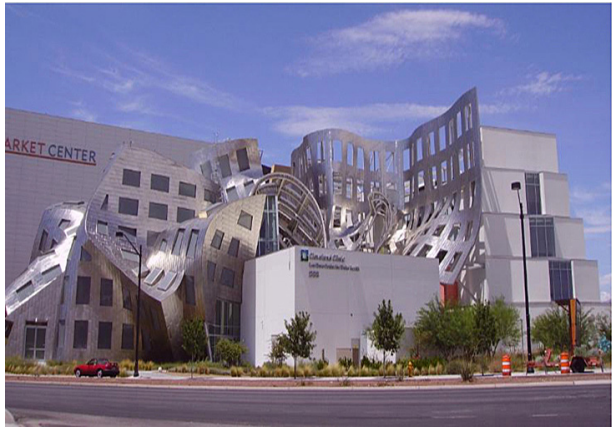

haver um total de $328 \mathrm{GCS}$, contabilizando um acréscimo de $5 \%$ nos últimos dois anos. Os planejadores urbanos do condado e da cidade de Henderson estimavam, em 2011, que 50\% dos CID implantados em seus limites geográficos já eram fisicamente fechados (Silva, 2012).

Dois exemplos são ilustrativos de como essa tendência se fortaleceu. 0 primeiro ocorreu na cidade de Las Vegas, quando a administração municipal tornou a formação da associação de proprietários (HOA) uma condição para o licenciamento de novos empreendimentos residenciais com mais de quinze unidades, muito embora não existisse essa obrigatoriedade legal. Os empreendimentos mais antigos passaram a ser também estimulados por outras iniciativas. Também, o cercamento de seus perímetros, de todos eles, era visto com bons olhos pelo poder local, por permitir transferir responsabilidades de manutenção de vias e espaços livres aos moradores, desonerando seus gastos e facilitando manter seu o ritmo de crescimento acelerado. Isso fez com que $100 \%$ dos novos empreendimentos tendessem a serem CID (McKenzie, 2005). 
Figura 3 - Uma nova fronteira imobiliária se expande no subúrbio, no meio do deserto

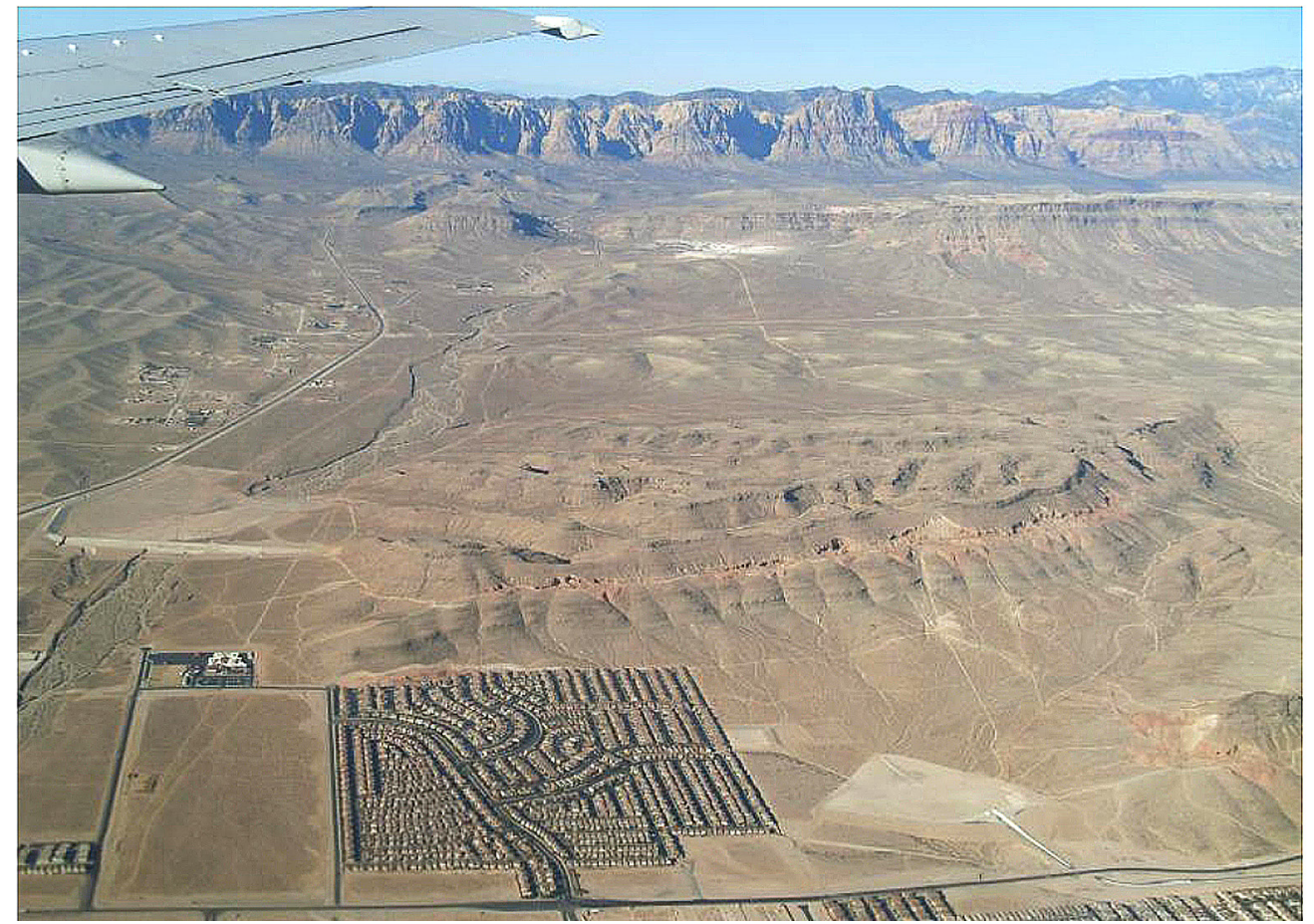

Fonte: Acervo da autora (2011).

0 caso do empreendimento Bonzana Village, um antigo subúrbio edificado em 1946, distante da área central, com 168 lotes de grandes dimensões, que permitia à população original ter um estilo de vida semirrural, com criação de animais como galinhas e cavalos, foi transformada em uma GC. A expansão urbana teria feito com que nos anos 1980 essa área já estivesse localizada a aproximadamente quatro quilômetros do centro, valorizando-a comercialmente e atraindo novos residentes. Esses últimos, diferentes dos primeiros, almejavam uma moradia de prestígio e começaram a reivindicar mudanças, entre elas subir seus muros, por entenderem imprimir maior valor ao mesmo. Na década de 1990, essa área foi incluída no perímetro objeto de um projeto de requalificação do centro, quando então os interesses públicos se uniram claramente aos privados dos novos moradores. Através de uma longa disputa judicial em que predominaram meios antidemocráticos e inescrupulosos, multas injustas e ameaças àqueles contrários aos interesses desses, esse empreendimento tornou-se uma GC (McKenzie, 2005).

0 segundo exemplo se deu ao norte do Vale, na cidade de North Las Vegas historicamente espaço de pobreza e violência, que nos anos 1990 quadruplicou sua população mantendo essa imagem. Na visão dos planejadores 
urbanos da cidade, atrair empreendimentos de classe média e alta seria o melhor meio de transformá-la. Seus incentivos acabaram por atrair um enorme $C I D$, Aliante, que se localizou nas suas franjas urbanas, foi orientado para uma população de renda média-alta, restrito a pessoas com mais de 55 anos. Sua implantação não logrou os resultados esperados. A imagem negativa de North Las Vegas permaneceu, só que passou a conviver com um bolsão de riqueza, fisicamente isolado do restante da cidade, conhecido como "triângulo dourado", o qual estimulou a chegada de outras $G C$ nas suas proximidades. A intencionada "gentrificação" da área não promoveu seu desenvolvimento, mas tão somente reforçou segregação e aproximou desigualdades (Silva, 2012).

Em relação à teoria do $N U$, verifica-se que seus princípios permeiam as ideias, discursos e projetos dos planejadores dos setores públicos e privados. ${ }^{34} 0$ setor de planejamento do condado, durante o pico do mercado imobiliário, afirmava ser a teoria do $N U$ a melhor opção para controlar o crescimento. Altas densidades, o uso misto, maior conectividade e inclusão de projetos multifamiliares fariam parte de uma fórmula ideal para reduzir os efeitos adversos observados no tráfego e na segurança pública. Ressaltamos que fica aqui explícita a similaridade entre o discurso dos defensores do $N U$ e os interesses da indústria da construção civil (Silva, 2012).

A empresa Focus Property Group, de maior expressão durante o boom nesta área do país nos anos 2000, lançou um sofisticado empreendimento com 11.500 residências, chamado de Inspirada, ${ }^{35}$ um projeto divulgado como protótipo do NU (Schumacher, 2004, p. 191). 0 projeto Inspirada está localizado no extremo limite do Vale, na cidade de Henderson. Quando ainda estava em processo inicial de construção e ocupação, foi surpreendido pela crise de 2008, quando passou a amargar grandes dificuldades financeiras. 0 projeto visivelmente mais adensado, com pequenos jardins frontais e casas tomando quase todo o lote, seguia o novo padrão de suburbanização predominante. Em 2011, não dispunha ainda de quase nenhum equipamento comercial e de serviço projetado, o que fazia seus moradores dependerem de percorrer longas distâncias para suprir as necessidades básicas. Placas de segurança privada eram comuns nas fachadas deixando explícito o sentimento de insegurança de seus moradores. Mesmo considerando que o projeto estava inacabado, é importante verificar que o desmantelamento do mercado imobiliário provocou a incerteza se conseguiria ser concluído e quando, tornando-o por alguns anos mais um $C I D$, igual a tantos outros que se distribuem dispersamente no meio do deserto dessa área, reforçando problemas citados neste trabalho.

\section{Conclusão}

Observamos que, na prática, os projetos do $N U$ se assemelham às GCs na forma física (designs sofisticados, pacotes de serviços especiais e por priorizar a localização suburbana), na forma legal (são na maioria condomínios) e no modelo de gestão de seus territórios (organizados em associações de proprietários). As duas soluções, $N U$ e $G C$, ainda se aproximam, quando buscam criar um "sentido de comunidade", defendem as altas densidades e os contratos mais rígidos como forma de manter inalterado o ambiente. 
Ambos intencionam proteger o valor do bem imóvel, gerar maior lucratividade aos empreendedores e reduzir gastos públicos, seja com uma nobre intenção de "sustentabilidade" ou com mero fim mercadológico.

As parcerias público-privadas, realizadas entre o final da década de 1980 e início dos anos 2000 no centro, tiveram a mesma grandiosa intenção e pífios resultados. Esses esforços de revitalização lograram ser vistos como amplos e sistematizados, com a pretensão de grandes reformulações econômica, social e política e a democratização do espaço urbano. No entanto, podemos dizer que Las Vegas apenas repetiu fórmulas já tentadas em tantos outros lugares, que ofereceram rápidos e incompletos ciclos de valorização imobiliária, os quais, por momentos, atraíram o capital privado; validando mais uma vez os estudos da "renda diferencial" de Neil Smith (1996).

As tendências parecerem contribuir para consolidar o que Neil Smith (1996) chama de "Novo Urbanismo Revanchista", quando se observa que tanto os projetos de revitalização das áreas degradadas, quanto naqueles de expansão urbana - em grande parte, seguidores da teoria do $\mathrm{NU}$ ou se constituindo $G C$ - continuam a promover a suburbanização e gentrificação e a viabilizar facilidades e direcionar vultosos investimentos públicos para áreas que permitem maior lucratividade aos investidores privados.

\section{Maria Floresia Pessoa de Souza e Silva}

Prefeitura Municipal de Natal, Secretaria de Informação, Planejamento Urbanístico e Ambiental. Natal/RN, Brasil.

mfpss2007@hotmail.com

\section{Notas}

(1) Traduzido do original: "The term 'sprawl' became a new Americanism as subdivisions and shopping centers sprouted across the landscape. In the late 1970s, when high interest rates and doubledigit inflation were pushing home prices beyond the reach of young families, the Department of Agriculture announced that three millions of acres prime farmland were being lost each year to suburban development. By 1985 reasonable people could debate whether the United States was a racist nation, an imperialist nation, or a religious nation, but scarcely anyone could quarrel with its designation as a suburban nation".

(2) Os autores alegam que a grande influência da Escola de Chicago, negando a existência desse padrão de ocupação disperso da indústria que antecedeu a Primeira Guerra Mundial, massificou a imagem dos círculos concêntricos com a indústria localizada no centro (Walker e Lewis, 2004, p. 18).

(3) Traduzido do original: "Clear, no single answer can be held accountable for such important phenomenon, but I will argue that there were two necessary conditions for American residential desconcentration - the suburban ideal and population growth - and two fundamental cause racial prejudice and cheap housing". 
(4) Acusado de desperdiçar terra, demandar alto custo de energia e transportes, desestruturar áreas agriculturáveis, criar paisagens repetitivas e monótonas; favorecer o desinvestimento e declínio dos centros urbanos; estimular a divisão, exclusão e segregação de classes, rendas e etnias; entre outras.

(5) No final da década de 1950, a aquisição do solo representava 11\%, em uma progressão contínua, vinte anos depois já representava 25 a 30\% dos custos de produção (McKenzie, 1994).

(6) Recrudesce a imagem do crescimento insustentável, quando sua população agora representa $5 \%$ da mundial, consume $1 / 4$ do petróleo produzido no mundo, sendo em média $60 \%$ desse utilizado nos seus deslocamentos cotidianos (Couch, Leontidou e Petschel-Held, 2007, p. 14).

(7) Traduzido do original: "[...] The most convincing answer to the question of why sprawl has persisted over so many centuries seems to be that a growing number of people have believe it to be the surest way to obtain some of the privacy, mobility and choice that once were available only to the wealthiest and most powerful members of society".

(8) Por exemplo, o relatório da American Society of Planning Officials (1960); New Approaches to Residential Land Development (1961) e Inovations versus Traditions in Community Development (1963) viabilizadas pela associação nacional de construtores e de outras instituições privadas.

(9) O setor imobiliário passa agora a ser parte dos negócios de grandes corporações, tais como: Gulf Oil, Humble Oil, Goodyear Tire and Rubber, Westinhouse, General Eletric, US Steel, Alcoa, National Gypsum, Pennslylvania Railroad, Chrysler, Ford Motor Corporation, Prudential Insurance Company, dentre outras (McKenzie, 1994; Babcock, 1965).

(10) Traduzido do original: Each proposal is judge in its particular merits, and the standards by which each proposal will be judge are vague. In effect, the Planned Unit Development device supplants the preexisting zoning. Covenants and easements bargained for between developer and municipality take place of costumary zoning regulations [...]".

(11) Traduzido do original: "The emergence of a fortress mentality and its phenomenal success are surprising in the United States, where most of the people live in open and unguarded neighborhoods. (...).. Living in a gated community represents a new version of the middle-class American dream. Precisely because it temporarily suppressed and masked, even denies and fuses, the inherent anxiety and conflicting social values of modern urban and suburban lives".

(12) Traduzido do original: "The rent gap is the disparity between the potential ground rent level and the actual ground rent capitalized under the present land use (...). the rent gap is produced primarily by capital devalorization (which diminishes the proportion of the ground rent able to be capitalized) and also continued urban development and expansion (which has historically raised the potential ground rent level in the inner city) [...] Only when this gap emerge can investment be expected since IF the present use succeeded in capitalizing all or most of the ground rent, little economic benefit could be derived from redevelopment. As filtering and neighborhoods decline proceed, the rent gap widens. Gentrification occurs when the gap is sufficiently wide that the developers can purchase structures cheaply, can pay the builder's costs and profit for rehabilitation, can pay interest or mortgage and construction loans, and can then sell the end product for a sale price that leaves a satisfactory return to the developer. The entire ground rent, or larger portion of it, is now capitalized; the neighborhood is thereby 'recycled' and begins a new cycle of use". 
(13) Traduzido do original: "The term, coined by Ruth Glass in 1964 has mostly been used to describe the residential aspects of this process but this is changing, as gentrification itself evolves".

(14) Seus estudos tomaram por referência número de reformas, demolições e de novas construções; preços de aluguéis; renda da população e adimplência quanto aos impostos sobre propriedades.

(15) Traduzido do original: "[...]This analysis reveals obvious growth on the periphery of cities in the past thirty years but much less change in population and real estate investment in the inner core than much of the literature on contemporary suburbanization implies. The areas of greatest decline and volatility are generally not in the inner city, but rather in the inner suburbs. Finally, at a less abstract scale, three emergent forms appear to dominate the neoliberal spatial fix. Suburbanization continues at a rapid pace, but is not a simple extension of the Keynesian managerialist patterns. Current outward growth appears to be deeply connected to the broader social polarization. The places of most active suburban growth are often places where second homes and leisure activities dominate. By contrast, the suburban housing of the Keynesian managerialist period (inner suburbs) is largely falling victim to disinvestment, as the wealthy flee for either the gentrified neighborhoods of the inner city or the gated ones of the exurbs. The inner core, moreover, appears to be revalorizing in a variety of cities, casting some doubt on the description of gentrification as an isolated neighborhood process".

(16) No Brasil geralmente chamados de Grandes Projetos Urbanos - GPU, operações urbanas, entre outras denominações.

(17) Ver artigos de Mike Davis, David Harvey, entre outros publicados em Sprawl and Suburbia: $A$ Harvard Design Magazine Reader William Saunders (nov 1, 2005); o livro Voices of Decline: The Postwar Fate of US, de Robert A. Beauregard (Nova York/London, Routledge, 2003).

(18) Traduzido do original: "Abandoned and underutilized buildings and declining economic activity are not limited to cities. Indeed, many older suburban communities are now falling victim to the same cycle of decline.[...] As the cycle of decline spread outward from the urban core, these aging suburbs began to experience many of the same problems as the cities. Household incomes dropped, crime increased, schools became troubled, signs of blight were apparent - all of which accelerated the move to yet more distant suburbs".

(19) Meados da década de 1990, o lote médio habitacional no país era em torno de $923 \mathrm{~m}^{2}$, em 1999, passa a $813 \mathrm{~m}^{2}$, enquanto a casa média cresce de $140 \mathrm{~m}^{2}$ para $186 \mathrm{~m}^{2}$ (Bruegmann, 2005, p. 68).

(20) Traduzido do original: "Rather than declining, many suburbs, usually those with natural amenities and particularly good access, have become increasingly gentrifies. One of the most visible results of this has been the dramatic rise of the number of teardowns: the replacement of smaller houses with much larger ones."

(21) Ver artigo "Teaching New Urbanism", publicado em outubro de 1997, pelo jornalista Alex Marshall (Macedo, 2007, p. 18).

(22) Novaiorquino, criado em Cuba, arquiteto urbanista, mestre pela Yale School of Architecture, possui dois títulos honorários de doutor. Fundou em Miami, em 1980, com sua esposa Elizabeth Plater-Zyberk, a companhia Duany Plater Zyberk \& Company (DPZ), líder nacional do NU e autora de projetos ícones como o Seaside (Flórida) e Kentlands (Maryland). Membro emérito no conselho do Congress for the New Urbanism, coautor dos livros Suburban Nation: The Rise of Sprawl and the Decline of the American Dream and The New Civic Art (http://en.wikipedia.org/ wiki/Andr\%C3\%A9s_Duany). 
(23) Traduzido do original: "Although NU communities are town-like in appearance, very few are incorporated as municipalities. Instead, they are rely primarily on covenants and restrictions and property owner's associations. On the one hand, the use of private covenants and restrictions offers opportunities for creative drafting to meet the specialized needs of the community. On the other hand, the mixed-use nature of New urban communities test the limits of the property owners's associations structure".

(24) No Brasil, Lara (2010) mostra que projetos urbanísticos divulgados na mídia brasileira como "protótipos" do New Urbanism desvirtuam completamente a teoria. Na prática, sua arquitetura plagia "nostalgicamente" o "estilo mediterrâneo da Flórida"; são enclaves residenciais completamente murados, servindo da forma mais esdrúxula aos propósitos do mercado imobiliário. A propaganda, direcionada aos consumidores de alta renda frisa a oferta de serviços e equipamentos sofisticados, a não diversidade e a não acessibilidade como atrações do projeto. Sua localização nos subúrbios significa dependência a uma infraestrutura viária deficiente e mal mantida, e difícil acesso aos transportes públicos.

(25) Cf. <http://www.newurbanism.org/newurbanism.html>. Acesso em: 15 ago 2011.

(26) Traduzido do original: "But this article argues that, upon close review, many critiques of the New Urbanism display characteristic flaws. Chief among these are the use of caricature, inadequate sampling of projects, deficient understanding of New Urbanist principles and practices, premature judgments, unrealistic expectations and ideological bias. In the end, the New Urbanism cannot satisfy all of its critics, because they demand contradictory changes. The left faults New Urbanism for not producing a radical critique of capitalism, while right-wing economists attack its support for regional planning. Architects and planners criticize New Urbanism for not being suficiently 'urban', while devotees of sprawl oppose New Urbanist projects because the densities are too high. Perhaps New Urbanists have found a reasonable and principled middle ground between these extremes, and one that makes actual building possible".

(27) Para maiores detalhes, ver: <http://www.mostcostly.com/most-expensive-painting>.

(28) Os enclaves residenciais murados existiram em outros momentos nos Estados Unidos, atendendo a outros fins e realizados em contextos bem diversos dos que surgiram no final dos anos de 1950. Nessa nova versão, têm como "mérito" fazer proliferar muros e portões entre as residências de aposentados e da classe média (Low, 2010).

(29) A forma como foi conduzida esta survey foi alvo de diversas críticas, para maior aprofundamento ver tese da autora, Silva (2012).

(30) Traduzidos dos respectivos originais: "approaches to development with radically divergent aims and values may inadvertently lead to similar results in suburban enclaves: landscapes of privilege that separate and divide" e "represent the ascendance of private over public Interests".

(31) O Vale inclui as cinco cidades - Boulder City, North Las Vegas, Cidade de Las Vegas, Henderson e Mesquite, várias vilas (towns), além de uma área urbana e outra rural pertencentes ao condado. O território dos estados nos Estados Unidos é dividido em condados. As áreas urbanas dos condados, via de regra, se tornam vilas (towns) ou cidades. Os chamados "condados urbanos" são uma tendência recente nos Estados Unidos, fruto da competitividade urbana.

(32) Entrevistas realizadas com planejadores públicos do condado em 2011, pela autora (Silva, 2012).

(33) http://www.usatoday.com/news/census/index. 
(34) Frequentes referências ao NU e ao Smarth Growth foram feitas durante as entrevistas realizadas aos mesmos durante a elaboração da tese de doutoramento da autora (Silva, 2012).

(35) O projeto do ME é de autoria da Quadrant Planning, uma empresa norte-americana, que ressalta no seu site ser filiada ao $N U$, dentre outras instituições.

\section{Referências}

BABCOCK, R. (1966). The zoning game. Municipal practices and policies. Londres/Madison, University of Wisconsin Press.

BLAKELY, E. e SNYDER, M. (1999). Fortress America: gated communities in the United States. Washington DC/Cambridge, Brookings Institution Press/Lincoln Institute of Land Policy.

BRUEGMANN, R. (2005). Sprawl: a compact history. Chicago, The University of Chicago.

CALLIES, D.; FREILICH, R. H. e ROBERTS, T. E. (2004). Cases and materials on Land Use. St. Paul, MN: West publishing co. American Casebook Series.

CALTHORPE, P. (2000). "The metropolitan region is a fundamental economic unit of the contemporary world. Governmental cooperation, public policy, physical planning, and economic strategies, must reflect this new reality". In: LECCESE, M. e MCCORMICK, K. Charter of the New Urbanism. Nova York, McGraw Hill.

CHARTER OF NEW URBANISM (1996). Disponível em: http://www.cnu.org/charter. Acesso em: out 2013.

COUCH, C.; LEONTIDOU, L. e PETSCHEL-HELD, G. (2007). “Introduction: Definitions, theories and methods of comparative analysis". In: COUCH, C.; LEONTIDOU, L. e PETSCHEL-HELD, G. Urban Sprawl in Europe. Landscapes, Land-Use change and Policy. Oxford, Blackwell Publishing Inc.

DAVIS, M. (1993). Cidade de quartzo. Escavando o futuro de Los Angeles. Rio de Janeiro/São Paulo, Página Aberta Ltda.

DUANY, A.; PLATER-ZYBERK, E. e SPECK, J. (2000). Suburban nation: the rise of sprawl and the decline of the American dream. Nova York, Farrar, Straus and Giroux.

ELLIS, C. (2002). The New Urbanism: critiques and rebuttals. Journal of Urban Design, v. 7, n. 3, Carfax Publishing, Taylor and Francis Group, pp. 261-291.

FISHMAN, R. (1987). "Bourgeois utopias". The Rise And Fall Of Suburbia. Nova York, Basic Books.

GLASZE, G.; WEBSTER, C. e FRANTZ, K. (2006). Private cities: local and global perspectives. Studies in Human Geography. Londres/Nova York, Routledge.

GRANT, J. L. (2007). Two sides of a coin? New urbanism and gated communities. Housing Policy Debate, v. 18, n. 3, pp. 481-501.

GOTTDIENER, M.; COLLINS, C. C. e DICKENS, D. R. (1999). Las Vegas. The social production of all American cities. Malden, Blackwell. 
GUSTERSO, H. e BESTENAM, C. (orgs.) (2010). The insecure American. How we got there and what we should do about it. Berkeley/Los Angeles/Londres, University of California Press.

HACKWORTH, J. (2007). The Neoliberal City: governance, ideology and development in American urbanism. Nova York, Cornell University Press.

HANLON, B. (2007). The decline of older, inner suburbs: a new reality in the U.S. Baltimore, ProQuest.

HARVEY, D. (1992). Condição Pós-Moderna. São Paulo, Loyola.

(1996). Do gerenciamento ao empresariamento: a transformação da administração urbana no capitalismo tardio. Espaço \& Debates. São Paulo, ano 16, n. 39, pp. 48-64.

(2005). "The New urbanism and the communitarian trap: on social problems and the false hope of design". In: SAUNDERS, W. S. (ed). Sprawl and Suburbia. A Harvard Design Magazine Reader. Minneapolis, University of Minnesota Press.

HESS, A. (1993). Viva Las Vegas. After Hours Architecture. São Francisco, Chronicle Books.

JACKSON, K. T. (1985). Crabgrass Frontier. The suburbanization of the United States. Nova York, Oxford University.

KRIEGER, A. (2006). Where and how does the urban design happen. Harvard Design Magazine, n. 24, pp. 64-71.

LANG, R. e LEFURGY, J. B. (2007). Boomburbs. The rise of the American's Accidental cities. Washington DC, The Brookings Institution.

LARA, F. L. (2011). New (Sub)Urbanism and Old Inequalities in Brazilian. Gated Communities. Journal of Urban Design, v. 16, n. 3, pp. 369-380. Disponível em: http://dx.doi.org/10.1080/13574809.2 011.571160. Acesso em: out 2011.

LEE, L.; SLATTER, T.e WYLY, E. (2008). Gentrification. Nova York/Oxon, Routlegde.

LITTLEJOHN, D. (1999). “Introduction: The ultimate company town”. In: LITTLEJOHN, D. The real Las Vegas. Life beyond the strip. Nova York, Oxford Press.

LOW, S. (2010). "A nation of gated communities". In: GUTERSON, H. e BESTEMAN, C. The insecure American. How we got there and what we should do about it. Berkeley/Los Angeles/Londres, University of California Press/University of California.

MARCUSE, P. (2008). The new urbanism: the dangers so far. Rio de Janeiro/Mauad X.

MCKENZIE, E. (1994). Privatopia: homeowner associations and the rise of residential private government. New Haven, Yale University Press.

(2005). Constructing the pomerium in Las Vegas. A case of study of emerging trends in american gated communities. Housing studies. Londres, v. 20, n. 2, pp. 187-203.

(2010). "Emerging regulatory trend, power and competing interests in us common interest housing developments". In: BLANDY, S.; DUPUIS, A. e DIXON, J. Multi-owner housing. Inglaterra/ Estados Unidos, Ashgate.

MOEHRING, E. (2000). Resort city in the Sunbelt. 1930-2000. Reno, University of Nevada.

NELSON, R. H. (2009). The puzzle of local double taxation. Why do private community associations exist? The Independent Review, v. 13, n. 3, pp. 345-365. 
SCHUMACHER, G. (2004). Sun, sin and suburban. An essential history of modern Las Vegas. Las Vegas, Stephen Press.

SILVA, M. F. P. de S. (2012). Privative communities: transformando a gestão e o espaço urbano em Las Vegas - consequências e perspectivas para a recente urbanização americana. Tese de doutorado. Salvador, Universidade Federal da Bahia.

SMITH, N. (1996). The New Urban Frontier. Gentrification and the revanchist city. Londres/Nova York, Routledge.

(2006). "A gentrificação generalizada: de uma anomalia local à "regeneração" urbana como estratégia urbana global”. In: BIDOU-ZACHARIASEN, C. (org.). De volta à cidade: gentrificação $e$ revitalização dos centros. São Paulo, Annablume.

SOJA, E. W. (2000). Postmetropolis: critical studies of cities and regions. Oxford, Basil Blackwell.

SONORAN INSTITUTE (2010). "Growth and sustainability in the Las Vegas valley". In: SCHUMACHER, G. (2004). Sun, sin and suburban. An essential history of modern Las Vegas. Las Vegas, Stephen Press.

STILGOE, J. R. (1990). Borderland: origins of the American Suburb, 1820-1939. New Haven, Yale University Press.

US FEDERAL GOVERNMENT (2000). Building Livable Communities. Sustaining Prosperity, Improving Quality of Life, Building a Sense of Community. Produzido no governo de Bill Clinton e revisado junho de 2000.

WALKER, R. e LEWIS, R. (2004). "Beyond the crabgrass frontier: industry and the spread of North American cities, 1850-1950". In: LEWIS, R. (ed.). The manufacturing suburb: building work and home on the metropolitan fringe. Philadelphia, Temple University Press.

Texto recebido em 15/out/2013

Texto aprovado em $21 /$ jan/2014 